\title{
PROPOSIÇÃO DE UM MODELO DE EXPLORAÇÃO PARA MINERALIZAÇÕES DE ESTANHO E TUNGSTÊNIO EM GRANITÓIDES DO ESTADO DE SÃO PAULO
}

\author{
Rubens Borges da SILVA \\ Paulo Cesar PRESSINOTTI
}

\begin{abstract}
RESUMO
Este trabalho objetiva apresentar um modelo de exploração direcionado a detectar mineralizações de Sn e W associadas com granitóides no Vale do Ribeira, Estado de São Paulo, Brasil.

O método é baseado na análise interativa de vários mapas temáticos que consideram os fatores mais importantes (geológicos, geoquímicos, geofísicos e conceitos metalogenéticos) que indiquem a presença de depósitos.

Tal método de integração foi utilizado num programa exploratório que tem por finalidade achar mineralizações de $\mathrm{Sn}$ e W espacialmente relacionadas a plútons graníticos. O resultado do programa exploratório provou a eficiência do método na deteç̧ão das mineralizações de Sn-W do granito do Bairro dos Correas.
\end{abstract}

\section{ABSTRACT}

This paper aims to present an exploration model to localize Sn and W mineralizations associated with granitoids of the Ribeira Valley in the State of São Paulo, Brasil.

The method is based on the interactive analyses of several thematic maps concerning the most important factors (geological, geochemical, geophysical and metallogenetics concepts) that indicate the presence of deposits.

Such an integraded approach was used in an exploration program driven to find Sn-W mineralizations spatially related to granitic plutons. The result of the program has proved the efficiency of the method by detecting the Sn-W mineralizations of the Bairro dos Correas pluton.

\section{INTRODUÇÃO}

Objetiva-se neste trabalho propor um modelo de exploração (modelo de depósito e estratégia de exploração) aplicável no Estado de São Paulo, mormente no Vale do Ribeira, para descobrir mineralizações de estanho (Sn) e tungstênio $(\mathrm{W})$, espacial e geneticamente relacionadas com granitóides.

A intenção é apresentar um modelo de exploração que atenda às exigências de custo/benefício inerentes aos programas de exploração mineral. Conseqüentemente, considerando o aspecto pragmático da exploração mineral, tevese o cuidado de montar um modelo de exploração com independência em relação aos modelos geotectônicos existentes para a região do Vale do Ribeira, os quais, apesar de bem engendrados do ponto de vista teórico, ainda são bastante carentes de dados reais e comprobatórios.
Dentro deste contexto, a estratégia de exploração visa detectar indicações as quais conjuguem condições julgadas necessárias e suficientes para o aparecimento da mineralização.

A utilização deste modelo de exploração em parte do Vale do Ribeira resultou na descoberta das mineralizações de Sn e W do Granito Bairro dos Correas, cujo detalhamento já permite vislumbrar que o Vale, em sua porção paulista, está prestes a ter sua primeira mina de Sn e W.

\section{MODELO DE EXPLORAÇÃO}

A exploração mineral pode ser definida como um esforço científico para descobrir e obter um recurso natural, o qual é, por natureza, não renovável. A exploração mineral compreende a pesquisa para se descobrir, identificar e avaliar economicamente o referido recurso (DE GEOFFROY \& WIGNALL, 1984). A principal 


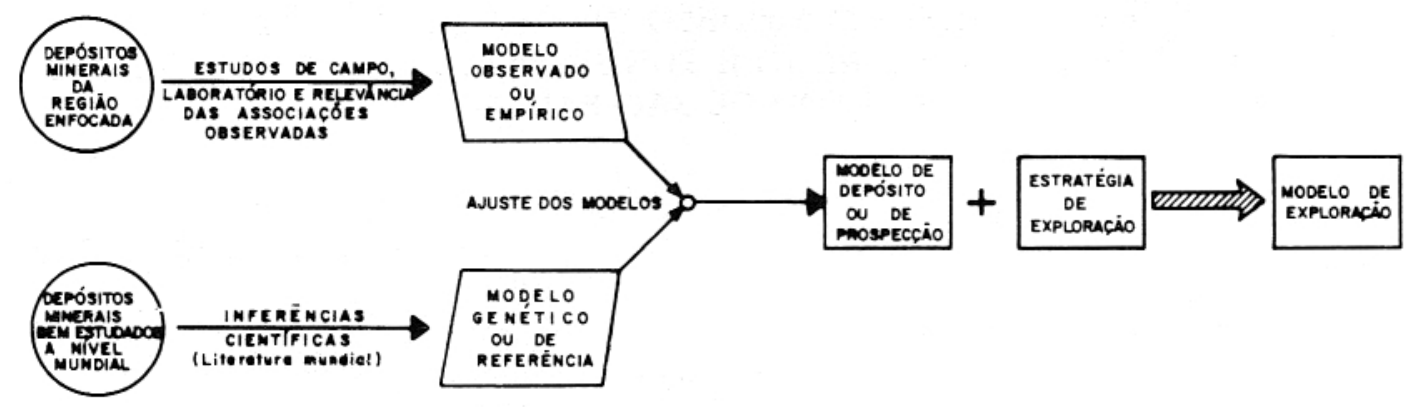

FIGURA 1 - Fases de elaboração do modelo de exploração.

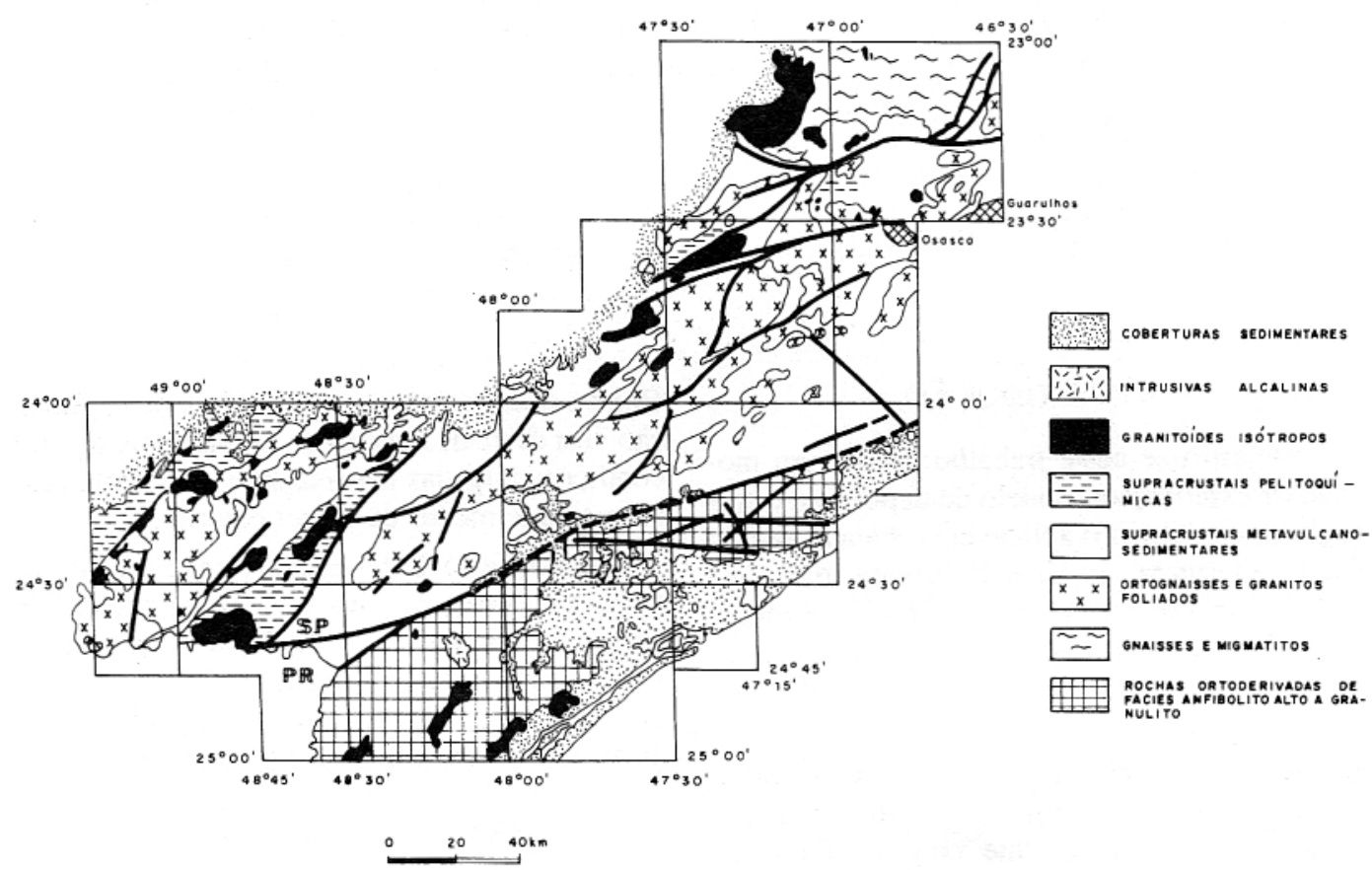

FIGURA 2 - Panorama Geológico da porção Sul-Sudeste de São Paulo. 

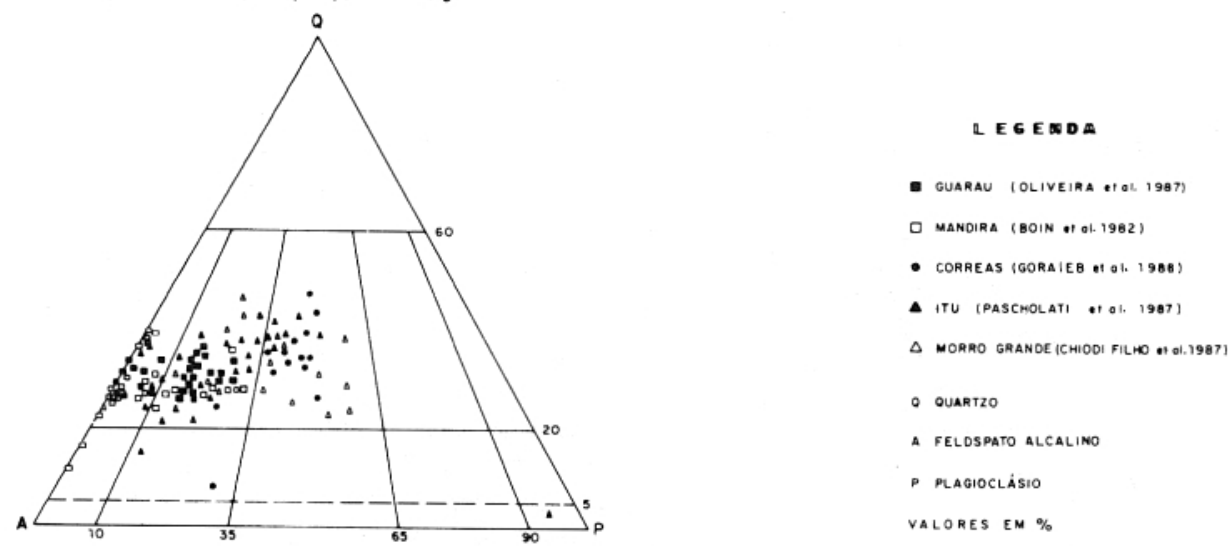

FIGURA 3 - Composição modal de granitos mineralizados de São Paulo e Paraná.

finalidade da exploração mineral é o sucesso, ou seja, achar o melhor depósito com o menor custo possível. Para atender a essa premissa do sucesso, a exploração mineral moderna utiliza como pedra de toque o modelo de depósito. Tal modelo corresponde ao conjunto de informações sistematicamente arranjadas que descrevem os atributos essencias de uma classe de depósito mineral. O modelo pode ser empírico, onde vários atributos são reconhecidos como essenciais mesmo que as relações entre eles sejam desconhecidas, ou conceitual, onde os atributos são relacionados através de um conceito fundamen-

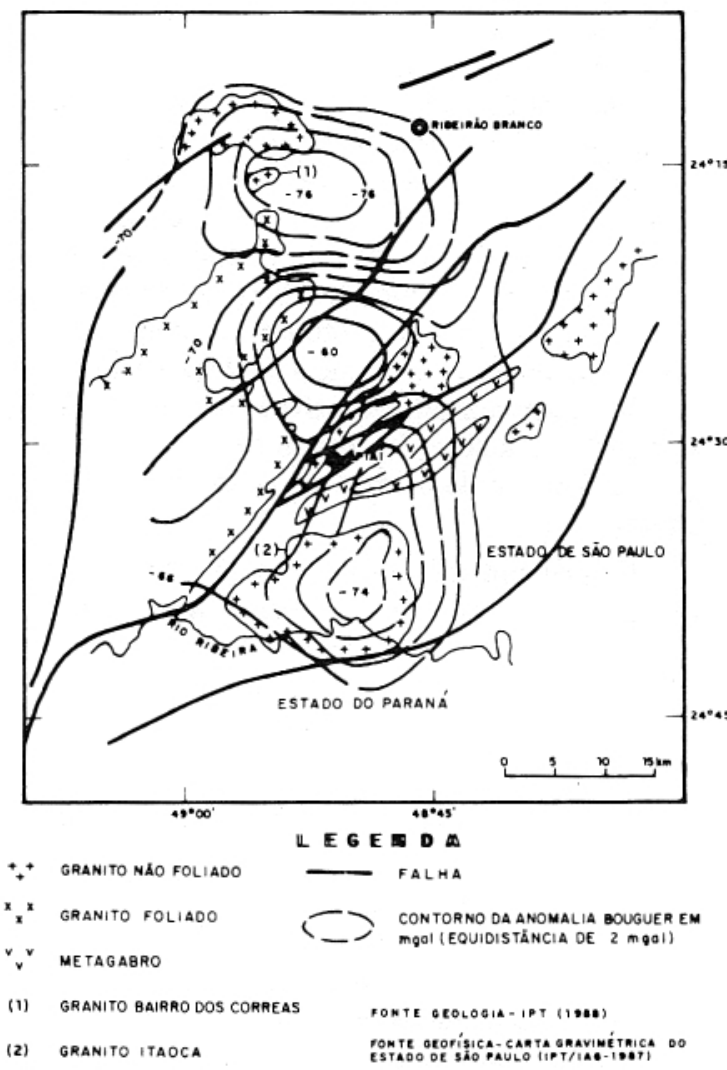

FIGURA 4 - Relação anomalia gravimétrica e granitóide mineralizado. tal. Nenhum modelo de depósito mineral é sempre estritamente empírico, pois seu desenvolvimento envolve observações científicas e julgamento da relevância das associações observadas. Na realidade, o modelo de depósito na exploração mineral não é um dogma científico, mas tão-somente uma hipótese de trabalho (WOODALL, 1984).

O estabelecimento de rigorosos modelos de depósitos é muito dificultoso não só pela falta de dados adequados como pelo entendimento bastante rudimentar de aspectos genéticos de diversos depósitos (e. g. Kipushi - $\mathrm{Cu}, \mathrm{Zn}, \mathrm{Pb}$ e Ge; Olympic Dam - Cu, Au e U - COX \& SINGER, 1986). Neste contexto, a base de conhecimento raramente permite ir além de comparações parciais entre áreas e depósitos minerais. Em tal situação, os conceitos genéticos são extremamente necessários para preencher as lacunas de conhecimento e, conseqüentemente, permitir a construção de um modelo de depósito.

\subsection{Modelo observado e modelo de referência}

Através de dados coletados na literatura, e de visitas às minerações selecionadas na região de interesse, é possível montar um modelo empírico, ou modelo observado. Este pode ser enriquecido com dados conceituais e se tranformar num modelo de prospecção, ou, então, numa situação mais comum, o observado é comparado e "ajustado" a um modelo genético mais adequado, selecionado dentre os vários existentes na literatura geológica (modelo de referência), o qual passa a ser o de prospecção (FIGURA 1).

No caso do Estado de São Paulo, as mineralizações consideradas para a construção do modelo observado foram as dos granitos Itu, Itaoca, São Francisco, Mandira, Guaraú e Bairro dos Correas. Através de dados obtidos na literatura, relatórios e visitas de campo, foi possível selecionar os seguintes aspectos, tidos como diagnósticos e proeminentes: 


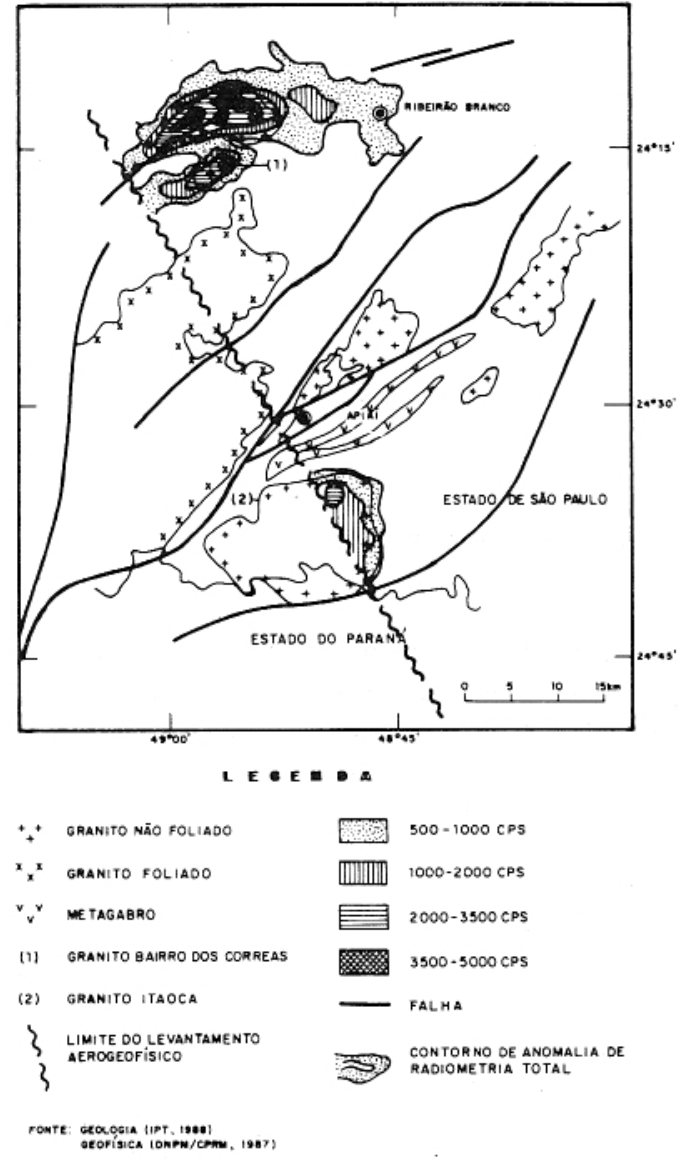

FIGURA 5 - Relação anomalia radiométrica e granitóide mineralizado.

a) os granitos relacionados com as mineralizações são granitos não-foliados, portanto sendo lícito admiti-los como tardi a pós-tectônicos (FIGURA 2);

b) os granitos são, no geral, corpos magmaticamente evoluídos, conforme ilustra a FIGURA 3;

c) com exceção do Granito Itaoca, onde a mineralização está associada a escarnito, nos demais corpos as mineralizações são do tipo greisen;

d) o Granito Itaoca é mineralizado a $\mathrm{W}, \mathrm{Cu}$, $\mathrm{Au}, \mathrm{Mo}$ e F; os granitos Itu e São Francisco a W, Sn e F; os granitos Guaraú e Mandira a Zn, $\mathrm{Cu}, \mathrm{Pb}, \mathrm{Sn}, \mathrm{F}$ e Mo; e o Granito Bairro dos Correas a $\mathrm{Sn}, \mathrm{W}, \mathrm{F}$ e $\mathrm{B}$;

e) no geral, os granitos apresentam tanto anomalias radiométricas totais quanto anomalias gravimétricas negativas, indicativas de alto grau de diferenciação magmática (FIGURAS 4 e 5);

f) são granitos circunscritos e detectáveis através de fotografias aéreas, imagens de satélite e mosaicos de radar; e g) alguns granitos hospedam veios gigantes de quartzo (e. g. Mandira, Bairro dos Correas e Itu), supostamente representantes de indicações positivas da atuação pretérita de sistemas de convecção, e, portanto, passíveis de terem se constituído em focos de atividades hidrotermais (FIGURA 6).

Com base nestes dados, buscou-se na literatura geológica internacional um modelo genético que englobasse estas características e pudesse ser adaptado para a situação geológica do Estado de São Paulo, conforme é demonstrado a seguir.

\subsection{Modelo genético}

A metalogênese preconiza para os modelos genéticos a necessidade da interação de vários fatores para a geração de um depósito mineral, os quais incluem: uma fonte de íons, uma fonte de fluidos, meio com porosidade e/ou sistema de fraturamento adequado, fonte de energia que pode ser calor magmático, calor radiogênico, calor de cristalização ou tectonismo - e um sítio de deposição adequado (FIGURA 7). Levando-se em consideração essas premissas, a metalogênese para depósitos associados com granitóides pode ser visualizada em duas etapas: uma fase de pré-concentração e outra fase de mineralização propriamente dita (LE FORT, 1987). A fase de pré-concentração é admitida como necessária para elementos com abundância crustal menor que 10 ppm (Sn, W, Mo, U, Hg, Ag, Se, As, Bi etc.), segundo PLANT et al. (1988), e pode acontecer por vários processos (baixa taxa de fusão parcial, alta taxa de cristalização fracionada, interação plutão/encaixante etc.) além da herança própria do protolito que originou o líquido magmático. Durante a evolução magmática os elementos incompatíveis (e. g. Sn, W, $\mathrm{F}, \mathrm{B}, \mathrm{Li}$ ) aumentam de concentração no líquido magmático, dando origem aos granitos especializados.

Os principais fatores de geração de depósito dependem dos processos presentes nos últimos estágios do magmatismo, quais sejam:

a) composição do magma ( $\mathrm{Sn}, \mathrm{W}, \mathrm{S}, \mathrm{Cl}, \mathrm{F}$, B) e, acima de tudo, do desenvolvimento de uma fase aquosa; e

b) profundidade de posicionamento do corpo granítico.

A evolução de uma fase aquosa a partir do magma é controlada principalmente pela solubilidade da água no líquido magmático, a qual é muito dependente da pressão e muito pouco da temperatura (BURNHAM \& OHMOTO, 1980). De acordo com Manning (1982 apud LE FORT, 1987), se o sistema for dominado por água, no 
GRANITÓIDE BAIRRO DOS CORREAS
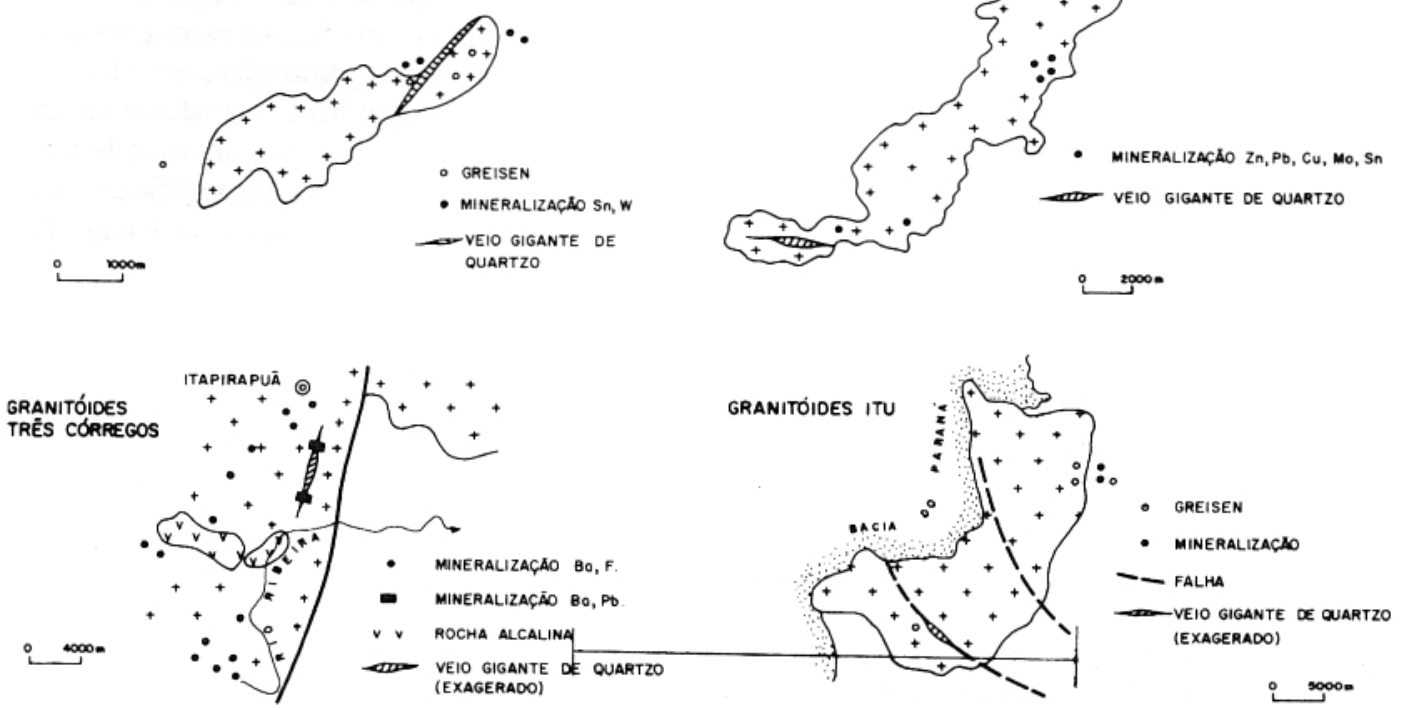

FIGURA 6 - Relação veio gigante, granitóides e mineralização.

magma, ele produzirá pegmatitos, mas, se existir uma combinação de água, F, B e Li, então o sistema será dominantemente hidrotermal.

Para que os granitóides atinjam níveis crustais rasos, devem ser deficientes em água, e para gerar mineralizações o magma necessita desenvolver uma fase aquosa. Estas duas condições antagônicas foram compatibilizadas no modelo de PLANT et al. (1983 e 1986), onde a

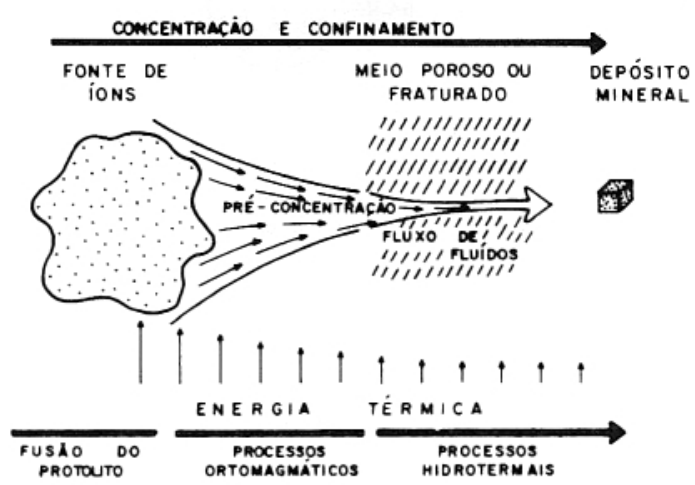

FIGURA 7 - Representação esquemática da interação de fatores essenciais para geração de depósitos minerais.

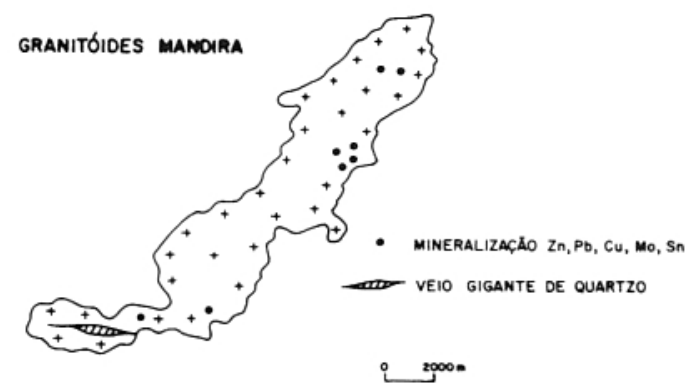

hidratação do magma é feita por fluidos das encaixantes a altas temperaturas, acarretando a retirada dos elementos formadores de minério, por redução dos minerais primários e acessórios. Numa dada profundidade é desenvolvida a fase fluida (second boiling) que juntamente com a tectônica regional determinam o grau de fraturamento e a atividade hidrotermal do sistema. Quando a pressão do fluido excede a resistência das rochas confinantes, acontece o hidrofraturamento, permitindo o escape de fluidos e marcando o início da instalação de células de convecção hidrotermal (fluidos magmáticos e meteóricos), que reagem com as porções solidificadas do granito e rochas encaixantes, removendo e transportando elementos mineralizantes, até iniciar a deposição dos minerais de minério através de neutralização das soluções mineralizantes. Isto ocorre tanto em função da natureza das encaixantes como em função da mistura com águas meteóricas. A FIGURA 8 sintetiza e ilustra os processos envolvidos na geração de um depósito de Sn e W, de acordo com o modelo de PLANT et al. (1983 e 1986).

\section{ESTRATÉGIA DE EXPLORAÇÃO}

Uma vez estabelecido o modelo de prospecção ou depósito (FIGURA 8), cria-se condição para se responder sobre o que, onde e de que forma deve-se procurar a mineralização ensejada. As respostas a essas perguntas constituem a estratégia de exploração, a qual, juntamente com o modelo de depósito, constitui o modelo de ex- 
ploração. A estratégia de exploração pode abranger três situações distintas (regional, distrital e local), onde cada uma tem objetivo e logística próprios em função da escala de investigação.

$\mathrm{Na}$ etapa regional, é importante ter conhecimento de teor e tonelagem dos depósitos já descobertos na região, para permitir decisões de investimentos econômicos com maior segurança.

As informações sobre controle, distribuição espacial com as encaixantes, morfologia e dimensões dos corpos mineralizantes são fundamentais nas etapas distrital e local.

\subsection{Estratégia regional}

O principal objetivo nesta etapa é selecionar, a nível de escala regional, áreas com potencial para conter mineralizações dos elementos desejados, no caso específico aqui considerado, o Sn e oW. Isso é conseguido através da utilização do conceito de domínio metálico de ROUTHIER (1980), bem como em função do mérito geológico da região considerada. As fontes de dados para essa avaliação são os mapas geológicos, mapas de ocorrências, mapas geoquímicos, províncias geoquímicas etc. (FIGURA 9). No caso do Estado de São Paulo, foi utilizada a justaposição dos domínios metálicos de F, Sn e W, pois as mineralizações conhecidas correspondem a es- carnitos e greisens com F, Sn e W; portanto, é de se esperar que áreas de recobrimento de tais domínios possam indicar uma situação muito favorável ao aparecimento de mineralizações desses elementos. Como as mineralizações estão, no geral, em cúpulas graníticas, introduziu-se um conceito modificador, que foi o de nível de erosão. As FIGURAS 10 e 11 exemplificam este procedimento no caso específico do Estado de São Paulo.

\subsection{Estratégia distrital}

O maior empenho é a seleção de áreas-alvo com possibilidade de conterem um tipo específico de depósito mineral, para posterior cheque de campo (estratégia local). Com base no modelo de prospecção (FIGURA 8), considerou-se como de maior relevância a conjugação de pelo menos três situações:

a) indicação da presença de corpo granítico diferenciado pós e/ou tarditectônico;

b) área bastante fraturada, favorável à circulação de fluidos; e

c) indicação de atuação pretérita de células de convecção, denunciadas pela presença de veios gigantes de quartzo, significando a interação rocha-água.

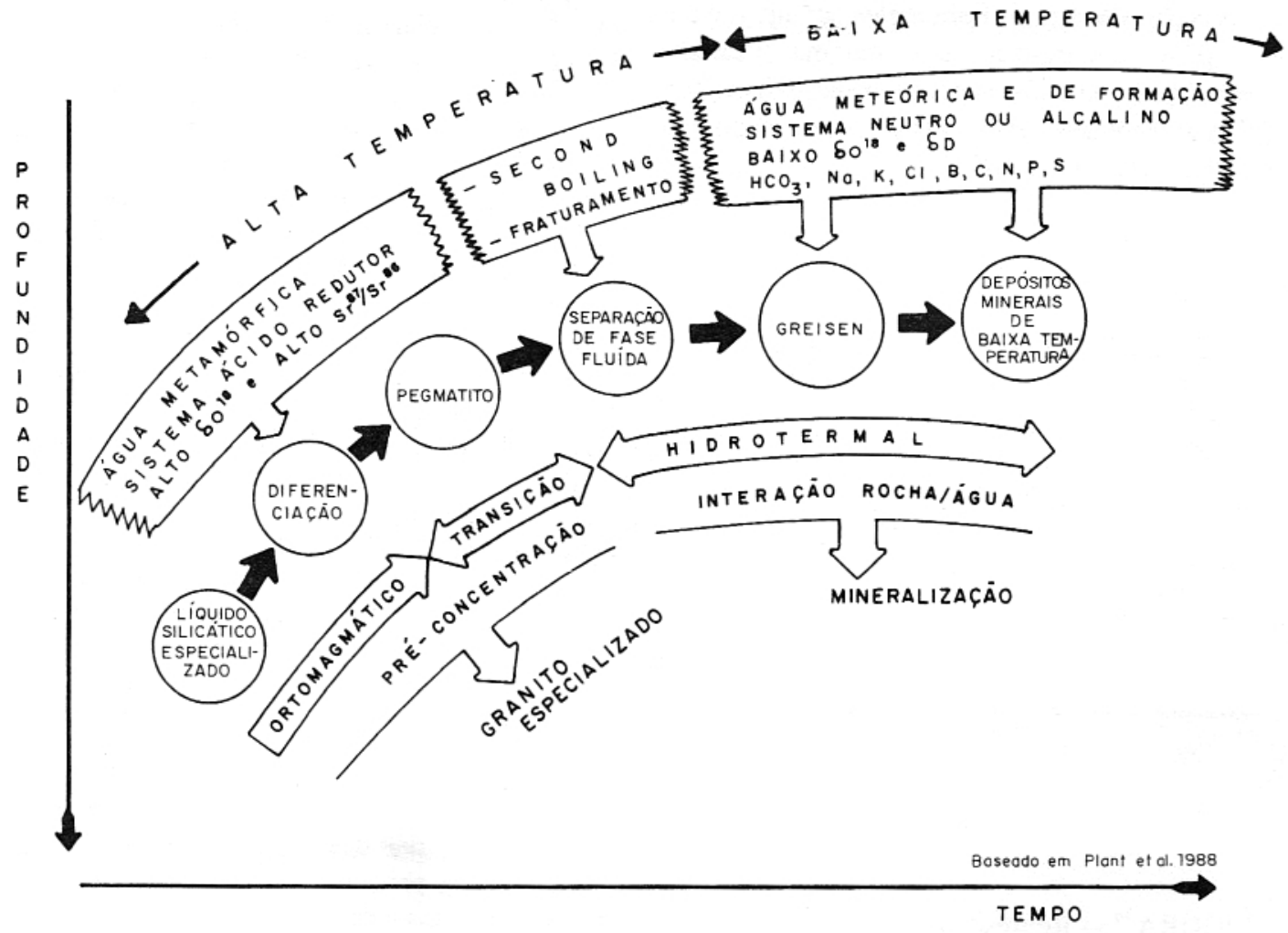

FIGURA 8 - Representação esquemática da metalogênese de Sn e W em granitos. 
QUADRO 1 - Comportamento dos elementos formadores de minério em rochas mineralizadas e não-mineralizadas.

\begin{tabular}{|c|c|c|c|}
\hline \multirow{2}{*}{ ELEMENTO } & \multirow{2}{*}{ ROCHA MINERALIZADA } & \multicolumn{2}{|c|}{ ROCHA NÃO-MINERALIZADA } \\
\hline & & ROCHA INTERMEDIÁRIA & ROCHA ÁCIDA \\
\hline $\mathrm{Li}$ & $\begin{array}{l}\text { micas de lítio (pegmatitos), } \\
\text { espodumênio, ambligonita. }\end{array}$ & $\begin{array}{l}\text { hornblenda, biotita e } \\
\text { feldspatos. }\end{array}$ & biotita e feldspato. \\
\hline $\mathrm{Rb}$ & $\begin{array}{l}\text { micas secundárias, argilas } \\
\text { (baixa temp.) feldspato } \mathrm{K} \\
\text { (adulária). }\end{array}$ & $\begin{array}{l}\text { biotita e outras micas, } \\
\text { feldspatos. }\end{array}$ & micas e feldspato $\mathrm{K}$. \\
\hline $\mathrm{Be}$ & $\begin{array}{l}\text { berilo, bertrandita, fenacita, } \\
\text { crisoberilo. }\end{array}$ & plagioclásio, moscovita. & plagioclásio, moscovita. \\
\hline $\mathrm{F}$ & $\begin{array}{l}\text { fluorita, topázio, vilhaumita, } \\
\text { apatita. }\end{array}$ & anfibólios, micas. & micas. \\
\hline $\mathrm{Cu}$ & sulfetos. & $\begin{array}{l}\text { piroxênios, anfibólios, bioti- } \\
\text { ta, magnetita. }\end{array}$ & $\begin{array}{l}\text { biotita }(\mathrm{Cu}-\mathrm{Mo} \\
\text { pórfiros). }\end{array}$ \\
\hline $\mathrm{Zn}$ & sulfetos. & anfibólio, biotita, magnetita. & biotita. \\
\hline $\mathrm{Pb}$ & sulfetos. & $\begin{array}{l}\text { feldspatos, minerais acessó- } \\
\text { rios ricos em U e Th. }\end{array}$ & $\begin{array}{l}\text { feldspatos e minerais } \\
\text { acessórios ricos em U e Th. }\end{array}$ \\
\hline $\mathrm{Nb}$ & $\begin{array}{l}\text { columbita, pirocloro, lopari- } \\
\text { ta e niobo-tantalatos. }\end{array}$ & $\begin{array}{l}\text { ilmenita, zircão, esfeno, } \\
\text { biotita. }\end{array}$ & $\begin{array}{l}\text { ilmenita, zircão, esfeno, } \\
\text { biotita. }\end{array}$ \\
\hline $\mathrm{Ta}$ & $\begin{array}{l}\text { tantalita, microlita, niobotan- } \\
\text { talatos. }\end{array}$ & $\begin{array}{l}\text { ilmenita, zircão, esfeno, } \\
\text { biotita. }\end{array}$ & $\begin{array}{l}\text { ilmenita, zircão, esfeno, } \\
\text { biotita. }\end{array}$ \\
\hline Mo & molibdenita, wulfenita. & $\begin{array}{l}\text { magnetita, ilmenita, esfeno, } \\
\text { plagioclásio. }\end{array}$ & $\begin{array}{l}\text { esfeno, feldspato } \mathrm{K} \text {, pla- } \\
\text { gioclásio. }\end{array}$ \\
\hline Sn & cassiterita, turmalina. & biotita, moscovita, ilmenita. & $\begin{array}{l}\text { biotita, moscovita, ilme- } \\
\text { nita. }\end{array}$ \\
\hline Cs & & biotita, moscovita. & biotita, moscovita. \\
\hline W & tungstatos. & biotita. & biotita. \\
\hline Th & monazita, torita. & $\begin{array}{l}\text { zircão, esfeno, biotita, mo- } \\
\text { nazita, apatita, xenotima, } \\
\text { alanita. }\end{array}$ & $\begin{array}{l}\text { zircão, esfeno, monazita, } \\
\text { apatita, biotita, xenotima, } \\
\text { alanita. }\end{array}$ \\
\hline $\mathrm{U}$ & $\begin{array}{l}\text { uraninita, petchblenda, fos- } \\
\text { fatos, hematita, martita, } \\
\text { niobo-tantalatos. }\end{array}$ & $\begin{array}{l}\text { zircão, esfeno, biotita, mo- } \\
\text { nazita, apatita, xenotima, } \\
\text { alanita. }\end{array}$ & $\begin{array}{l}\text { zircão, monazita, biotita, } \\
\text { apatita, xenotima, alanita, } \\
\text { esfeno. }\end{array}$ \\
\hline $\begin{array}{l}\text { Terras Raras } \\
\text { (TR) }\end{array}$ & $\begin{array}{l}\text { silicatos complexos, monazi- } \\
\text { ta, xenotima, alanita, niobo- } \\
\text { tantalatos. }\end{array}$ & $\begin{array}{l}\text { biotita, plagioclásio (Eu), } \\
\text { monazita, alanita, esfeno. }\end{array}$ & $\begin{array}{l}\text { apatita, zircão, micas (Ter- } \\
\text { ras Raras leves). }\end{array}$ \\
\hline $\mathrm{Ba}$ & Barita, cimerita, celsiana. & micas, plagioclásio. & micas e feldspatos $\mathrm{K}$. \\
\hline
\end{tabular}

fonte: PLANT et al. 1985. 
A FIGURA 12 sintetiza a estratégia de exploração, evidenciando os meios utilizados para a obtenção de cada indicação considerada como relevante para o aparecimento de um depósito. Esta estratégia é baseada na elaboração de vários mapas temáticos, que são interativamente correlacionados no sentido de se adicionarem evidências e critérios. A priorização das áreasalvo, selecionadas por esse processo, reflete a somatória dos vários graus de confiança que o exploracionista tem para cada parâmetro.

Para o Estado de São Paulo, os mapas temáticos utilizados foram os seguintes:

a) mapa geológico compilado: evidencia corpos granitóides pós-tectônicos (com base em elementos estruturais e fotogeológicos), corpos granitóides não foliados, rochas carbonáticas, rochas alcalinas e principais descontinuidades estruturais.

b) mapa de parâmetros vetoriais de lineamentos: utilizado para rastrear campos locais de fraturas, com azimutes distintos dos de cunho regional, e conseqüentemente rastrear intrusões tardi a pós-tectônicas, aflorantes e subaflorantes;

c) mapa morfoestrutural por assimetria de drenagem: é uma tentativa de detectar, através de morfoestruturas positivas, possíveis intrusões aflorantes e subaflorantes;

d) mapa de padrões de drenagem: utilizado para indicar áreas com possíveis plutões intrusivos aflorantes e subaflorantes;

e) mapa de densidade de lineamentos: utilizado para identificação das áreas mais fraturadas;

f) mapa de associações geoquímicas regionais: através das assembléias geoquímicas típicas de rochas granitóides, permite delimitar áreas com possibilidade de conterem intrusões aflorantes e subaflorantes;'

g) mapa da radiometria total: por meio do padrão de anomalia e pela conjugação com outros mapas temáticos, torna possível diferenciar áreas portadoras de corpos graníticos especializados em elementos radioativos, podendo significar granitos onde houve a separação de uma fase fluida aliada a eficientes fatores de concentração de elementos incompatíveis;

h) mapa gravimétrico: a correlação dos mapas gravimétricos com outros mapas temáticos pode indicar áreas portadoras de granitos magmaticamente evoluídos. Os granitos evoluídos constituem massas quartzo-feldspáticas com densidades contrastantes com as das rochas regionais, podendo-se manifestar em levantamentos gravimétricos como anomalias negativas;

i) mapa de distribuição de rochas carbonáticas: juntamente com outros mapas temáticos (e.g., mapas indicativos de intrusões graníticas) possibilita delimitar as áreas favoráveis para escarnitos; e

j) mapa de feições indicativas de veios gigantes de quartzo: a presença de veio gigante de quartzo supostamente representa a prova mais direta da atuação de processos hidrotermais. No caso do Granito Correas, é bastante ilustrativa a conjugação das FIGURAS 4 e 5 para exemplificar essa etapa de estratégia distrital.

\subsection{Estratégia local}

Nesta etapa, os objetivos maiores são a constatação da existência do corpo granítico, a nível aflorante ou subaflorante, e a comprovação da interação plutão/água e da existência de mineralização (FIGURA 13).

A interação rocha-água, além da presença de veio gigante de quartzo, pode ser checada com o auxílio do QUADRO 1, que relaciona minerais primários e secundários portadores de elementos mineralizantes em rochas mineralizadas e não-mineralizadas, bem como através de indicações propostas por PLANT et al. (1983), conforme se segue:

a) presença de processos autometassomáticos/tardimagmáticos (microclinização, moscovitização e albitização);

b) presença de processos metassomáticos pós-magmáticos (greisenização);

c) a ordem normal de cristalização da biotita e do quartzo mostra-se invertida;

d) alteração de feldspato para sericita e/ou caulinita, alteração dos minerais ferromagnesianos para clorita e/ou epídoto e calcita, hematitização e martitização dos minerais ferromagnesianos e da magnetita.

e) minerais acessórios são reduzidos para fases estáveis em baixa pressão e temperatura;

f) urânio e tório - que normalmente estão no zircão, alanita, biotita, apatita e xenotima passam para minerais secundários, como uraninita, petchblenda, hematita, martita e thorita;

g) a caracterização da assembléia dos minerais gerados pelo metamorfismo de contato quanto à pressão e temperatura permite estimar o nível de posicionamento estrutural da intrusão; e

h) a atividade hidrotermal perturba a correlação interelementos, bem como as razões $\mathrm{Rb} / \mathrm{Sr}$, $\mathrm{Rb} / \mathrm{Ba}, \mathrm{K} / \mathrm{Rb}, \mathrm{Sr} / \mathrm{Ba}, \mathrm{U} / \mathrm{Th}$ e $\mathrm{Mg} / \mathrm{Li}$. No caso de granitos não afetados hidrotermalmente, essas relações evidenciam o trend magmático. 


\section{COMENTÁRIOS FINAIS}

Além de apresentar um modelo de exploração para mineralizações de $\mathrm{Sn}$ e W em granitos do Estado de São Paulo, procurou-se também salientar o papel do modelo de depósito na formulação da estratégia de exploração, bem como mostrar que a exploração mineral é um trabalho de equipe, pois a elaboração e análise dos vários mapas temáticos exigem a atuação de profissionais com experiência em cada tema.

Deve ficar claro que nem sempre se dispõe das ferramentas mais adequadas para se executar a estratégia de exploração, conforme preconiza o modelo de depósito. Nessa circunstância, a experiência e a criatividade dos exploracionistas devem superar tais dificuldades.

A descoberta do depósito de Sn e W do Bairro dos Correas ilustra adequadamente essa situação. Quando a mineralização foi descoberta, ainda não se dispunha dos resultados dos levantamentos regionais de geoquímica e geofísica. Para tanto, foram de grande eficiência, entre os vários parâmetros considerados, os seguintes fatores:

a) o conhecimento da existência de granito isótropo naquela área através do mapa geológico da Folha Araçaíba, feito pelo IPT para o PróMinério em 1984;

b) as características estruturais do corpo granítico, detectadas através de fotografias aéreas, sugeriam posicionamento tardi a pós-tectônico, com grande chance, portanto, de ser um granito evoluído; e

c) indicação, com alto grau de certeza, da existência de um veio de quartzo gigante encaixado no granito e detectado por estudos de fotografias aéreas.

A utilização de modelo de depósito induz à ousadia de se prospectar em regiões já pesquisadas por outras companhias ou mesmo em áreas nunca dantes consideradas como favoráveis para o tipo de mineralização ensejado. Dentro desse contexto, o modelo de exploração é uma forma de otimizar a exploração mineral, a qual já vem sendo quantificada na medida em que a informatização vai-se incorporando aos programas de exploração mineral.

Entretanto, em decorrência da carência de estatística e bancos de dados referentes aos depósitos minerais, bem como do descompasso de desenvolvimento em relação aos países do Primeiro Mundo, em nações como o Brasil, a exploração mineral ainda dependerá por um bom tempo da experiência, bom senso e cultura geológica do exploracionista envolvido.

\section{AGRADECIMENTOS}

Os autores são gratos a Ana Candida Melo Cavani, pelo auxílio prestado na editoração deste trabalho, e ao colega Mário Lincoln De Carlos Etchebehere, pela leitura, críticas e sugestões apresentadas.

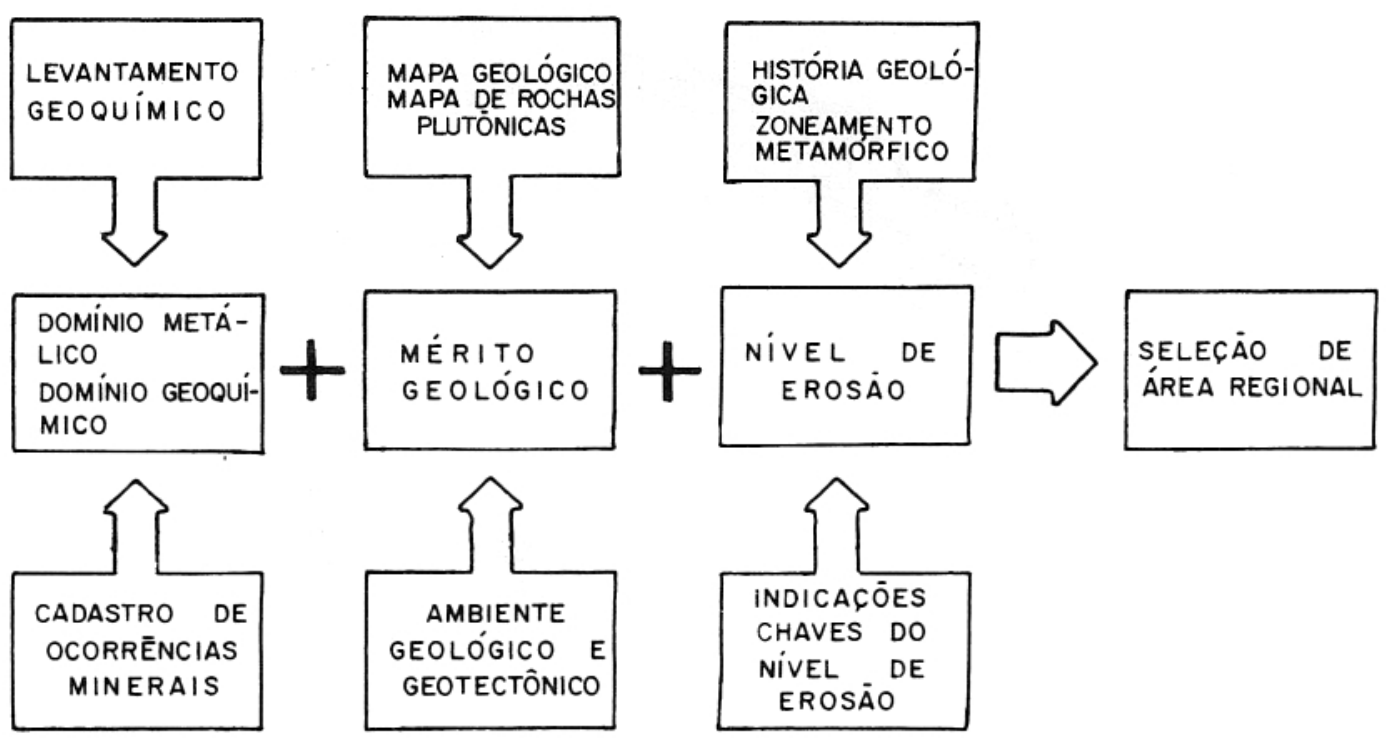

FIGURA 9 - Estratégia regional. 


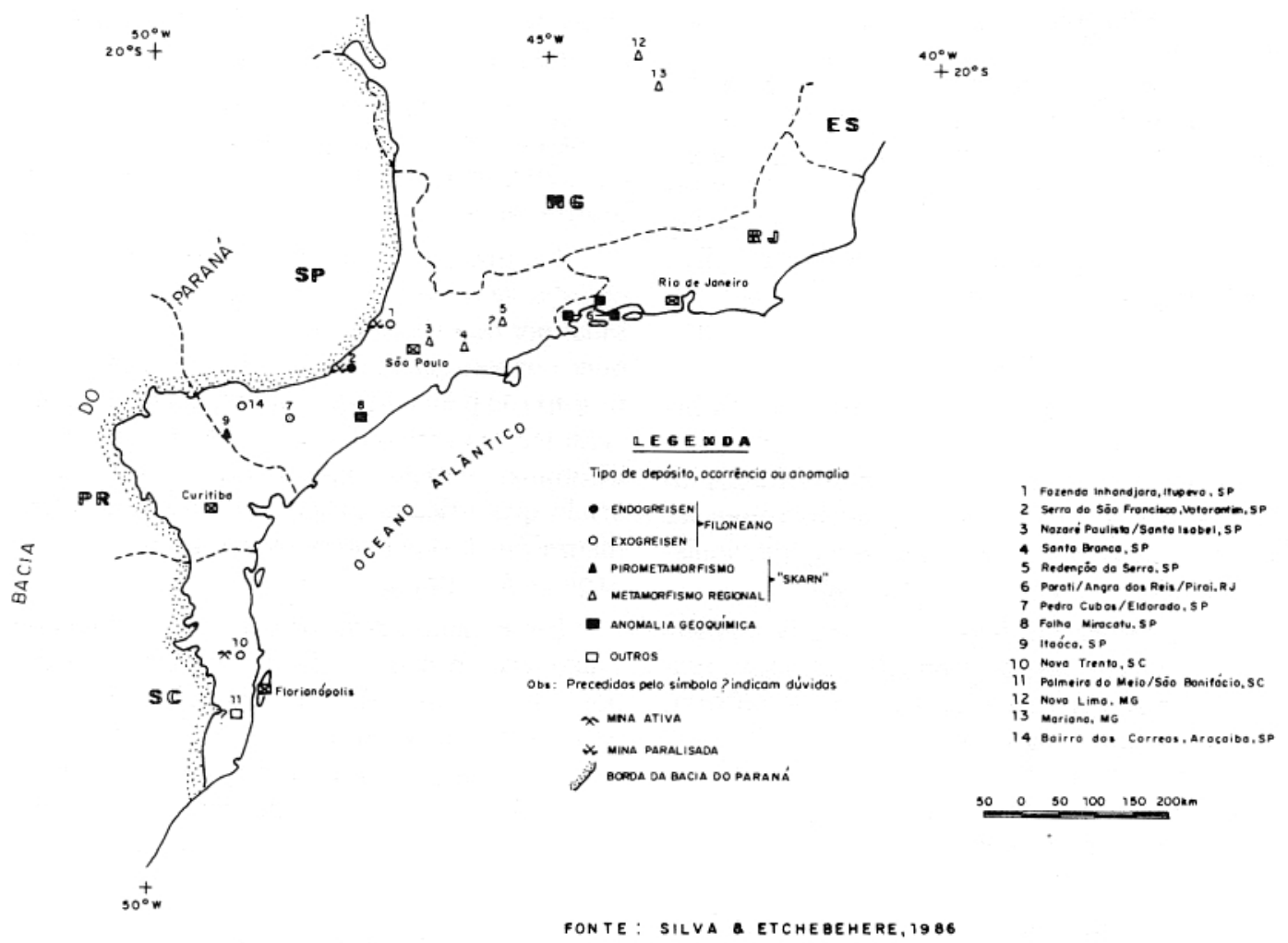

FIGURA 10 - Mapa de localização de indícios e minas de tugstênio e estanho na Região Sudeste.

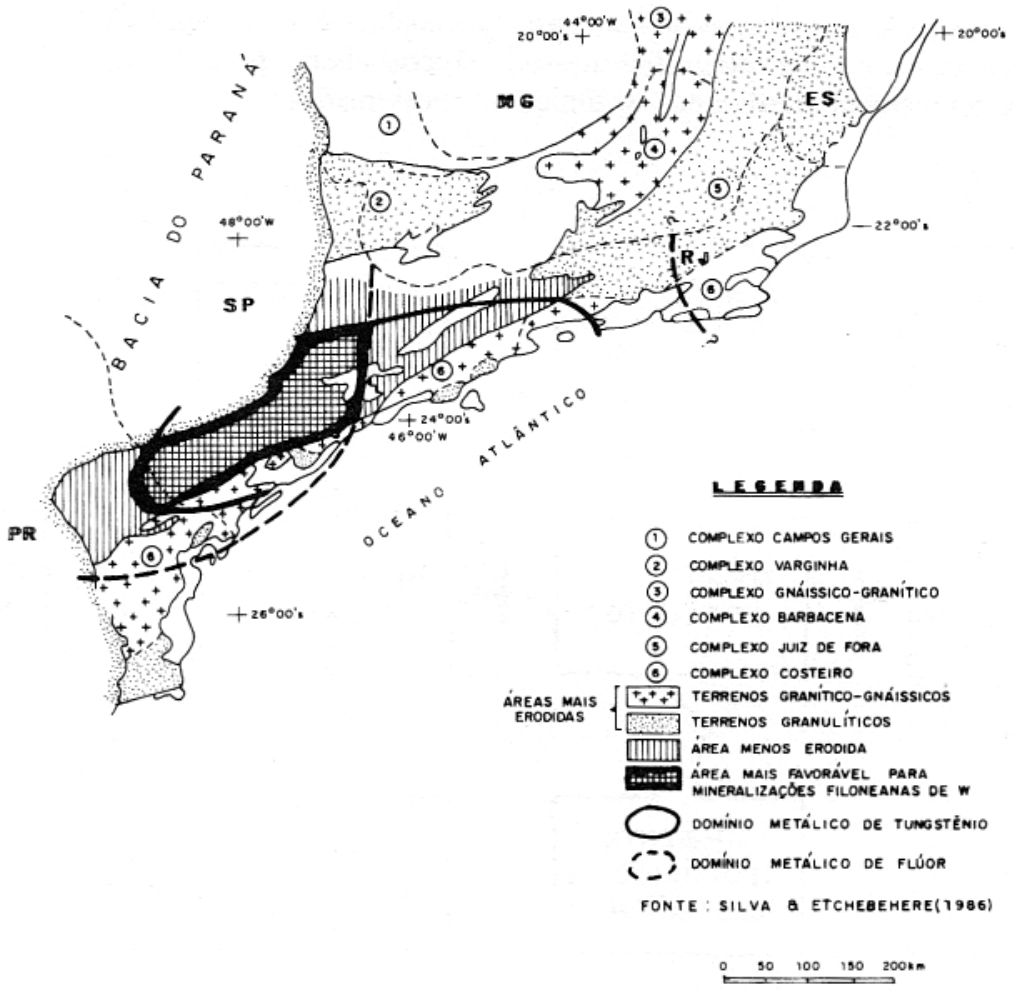

FIGURA 11 - Áreas mais favoráveis para mineralizações filonares hidrotermais de tungstênio e estanho. 


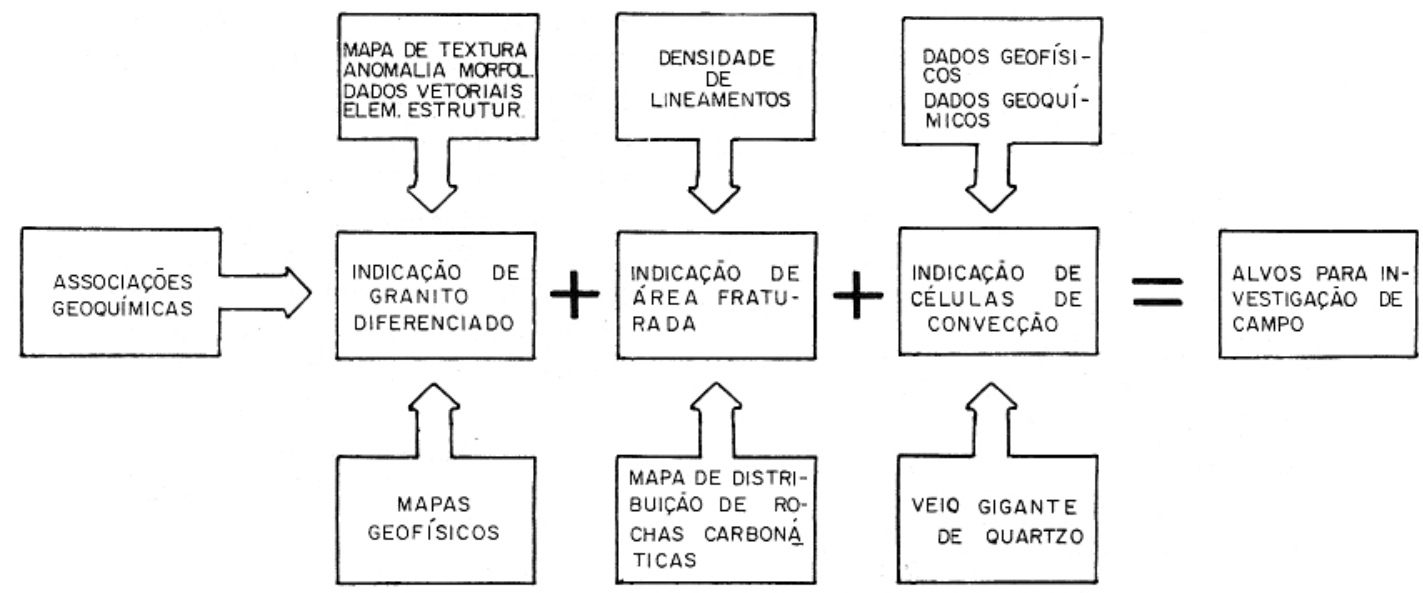

FIGURA 12 - Estratégia distrital.

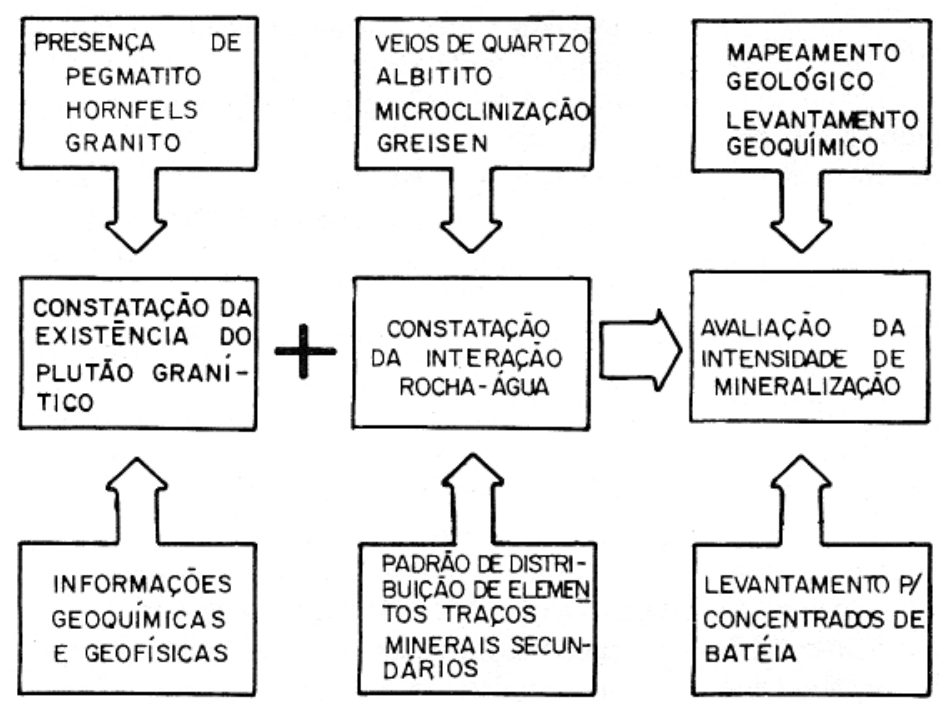

FIGURA 13 - Estratégia local.

\section{REFERÊNCIAS BIBLIOGRÁFICAS}

BOIN, M.N.; SILVA, J.R.B.; SILVA, R.B.; MELLO, J.S.C. 1982. Mineralizações polimetálicas hidrotermais associadas aos granitóides alcalinos de Mandira. In: CONGRESSO BRASILEIRO DE GEOLOGIA, 32, Salvador, 1982. Anais... Salvador. v.3, p. 945-956.

BURNHAM, C.W.; OHMOTO, H. 1980. Latestage processes of felsic magmatism. In: SOCIETY OF MINING GEOLOGISTS OF JAPAN. Granitic magmatism and related mineralization p. 1-11, (Mining Geology Special Issue, $\mathrm{n}^{\circ}$ ).
CHIODI FILHO, C.; MORETZHON, J.S.; SANTOS, J.F.; SOARES, P.C. 1987. Aspectos geológicos e metalogenéticos dos granitos Morro Grande, Piedade e Varginha Vale do Ribeira - Paraná. In: SIMPÓSIO SUL-BRASILEIRO DE GEOLOGIA, 3, Curitiba, 1987, Anais... Curitiba. v.2, p. 515-542.

COX, D.P.; SINGER, D.A. 1986. Mineral deposit models. United States Geological Survey, 379 p. (Bulletin, 1963).

DE GEOFFROY, J.G. \& WIGNALL, T.K. 1985. Designing optimal strategies for mi- 
neral exploration. $1^{\mathrm{a}}$. ed. New York, Plenum Press. 364 p.

DNPM/CPRM. 1987. Departamento Nacional da Produção Mineral/Companhia de Pesquisas de Recursos Minerais. 1987. Projeto São Paulo - Rio de Janeiro. Convênio $\mathrm{DNPM} / \mathrm{CPRM}$ (inédito)

GORAIEB, C.L.; OLIVEIRA, M.C.B.; MELLO, I.S.C.; SILVA, R.B. 1988. As mineralizações estano-tungsteníferas do Granito Correas (SP) In: CONGRESSO LATINOAMERICANO DE GEOLOGIA, 7, Belém, 1988. Anais... Belém, p. 154-172.

IPT. 1988. Avaliação preliminar das folhas (em 1:50.000): Taquaral, Mina do Espírito Santo, Ribeirão Itacolomi, Serra do Aboboral, Jacupiranga (Eldorado Paulista), Rio Guaraú (Barra do Azeite), Rio Turvo (Serra do Aleixo) - Vale do Ribeira, SP. Relatório IPT no 26.863. 4 volumes. Inédito.

IPT/IAG. 1987. Carta gravimétrica do Estado de São Paulo - Fase B. Relatório IPT n? 25.645. Inédito.

LE FORT, P. 1987. Mineralization of Sn, W, Mo and collision plutonism. Rev. Bras. Geoc. 17(4): 551-554.

OLIVEIRA, M.C.B.; RODRIGUES, E.P.; COUTINHO, S.M.V.; MARTINS, F.G.; FIGUEIREDO, M.C.H.; ZAPPAROLLI, L.H. 1987. Petrologia de parte do maciço granítico Guaraú - SP. In: SIMPÓSIO SUL-BRASILEIRO DE GEOLOGIA, 3, Curitiba, 1987. Anais... Curitiba, v.1, p. 571-664.

PASCHOLATI, E.M.; VLACH, S.R.F.; AMARAL, G. 1987. Contribuição ao conhecimento da suíte intrusiva de Itu. In: SIMPÓSIO DE GEOLOGIA REGIONAL, 6, Rio Claro. 1987. Anais... Rio Claro, p. 47-62.
PLANT, J.A.; SIMPSON, P.R.; GREEN, P.N.; WATSON, J.V., FOWLER, N. 1983. Metalliferous and mineralized caledonian granites in relation to regional metamorphism and fracture systems in Northern Scotland. Trans. Instn. Min. Metall. (sect B: Appl. earth sci.) 92. p. 33-48. ; OBRIAN, C.; TARNEY, J.; HURDLEY, J. 1985. Geochemical criteria for recognition of high heat production granites. In: High heat production (HHP) granites, hidrothermal circulation and ore genesis Inst. Min. Metall. London, p. 263-286. ; FORREST. M.D.; HODGSON, J.F.; SMITH, R.T.; STEVENSON, A.G. 1986. Regional geochemistry in the detection and modelling of mineral deposits. In: THORTON \& HOWARD (ed). Applied Geochemistry in the 1980s. London. Graham and Trotman. p. 102-139. ; HALE, M.; RIDGWAY, J. 1988. Developments in regional geochemistry for mineral exploration. Trans. Instn. Min. Metall. (Sect. B; Appl. earth sci.), 97. p. 116-140.

ROUTHIER, P. 1980. Où sont les métaux pour l'ávenir?, les provinces métalliques. Essai de metallogénie globale. 409 p. BRGM. (Memoir 105).

SILVA, R.B.; ETCHEBEHERE, M.L. De C. 1986. Contribuição ao estudo da potencialidade tungstenífera do Estado de São Paulo e critérios de prospecção. In: CONGRESSO BRASILEIRO DE GEOLOGIA, 34, Goiânia, GO, 1986, Anais..., Goiânia, SBG, v.5, p. 2.035-2047.

WOODALL, R. 1984. Sucess in mineral exploration: confidence in science and ore deposits models. Geoscience Canada 11(3): 127-132. 